\title{
CLASSIFICAÇÃO E TIPOLOGIA DOS LAPIÁS CONTRIBUTO PARA UMA TERMINOLOGIA DAS FORMAS CÁRSICAS
}

\author{
MARIA LUÍSA RODRIGUES ${ }^{1}$
}

\begin{abstract}
Resumo - A bibliografia que refere as formas que se desenvolvem em rochas carbonatadas tem tendência a dar destaque às chamadas formas maiores do carso (dolinas, uvalas, poljes e formas fluvio-cársicas), prestando menos atenção às formas de dissolução ditas menores compostas pelas formas lapiares ou lapiás. Neste campo a bibliografia escrita em português não constitui excepção. Daí a opção da escolha deste conjunto de formas entre o vasto leque das formas cársicas, para além do facto de serem estas formas, de dimensão mais reduzida, aquelas que evidenciam melhor a existência de processos de dissolução activos à superfície e que contribuem de maneira decisiva para o funcionamento hidrológico do carso subterrâneo. A maior parte das classificações dos lapiás são essencialmente descritivas, privilegiando a morfologia (formas e microformas), o que conduz a uma multiplicação dos termos, atribuindo um papel secundário à génese e aos processos ligados à sua formação. Tentou-se, assim, construir uma metodologia de classificação dos lapiás, e correspondente tipologia das formas, que, partindo dos processos de formação, acrescenta o tipo de cobertura e a morfologia. Individualizam-se três grandes conjuntos de lapiás: i) aqueles em que o processo dominante (associado à dissolução) se relaciona com a escorrência superficial da água; ii) as formas lapiares formadas pela acção conjunta da escorrência e da dissolução controlada por factores estruturais; iii) os lapiás com origem fundamentalmente bioquímica, resultantes da acção da dissolução (por permanência da água em superfícies deprimidas) e dos organismos vivos.
\end{abstract}

Palavras-chave: Lapiás, classificação genética, processos de formação, tipologia das formas, terminologia em português.

\begin{abstract}
CLASSIFICATION AND TYPES OF KARREN. A CONTRIBUTION FOR A KARST LANDFORMS TERMINOLOGY. The bibliography that refer to the forms developed in limestone rocks normally emphasizes the so called major karst forms (sinkholes, uvalas, poljes and fluvio-karstic forms), paying less attention to the so called minor karst forms, that are formed by the karren ones. In this particular field, the bibliography available in Portuguese is no exception. Hence the option of choosing this set of forms amongst all the wide range of karstic landforms, in addition to the fact that these smaller forms show better the existence
\end{abstract}

Recebido: Fevereiro 2012. Aceite: Julho 2012.

1 Investigadora do Centro de Estudos Geográficos (CEG) do Instituto de Geografia e Ordenamento do Território (IGOT) da Universidade de Lisboa. E-mail: luisa.rodrigues@campus.ul.pt 
of active dissolution processes at the surface that contribute decisively to the hydrologic underground karst activity. Most of the karren classifications are essentially descriptive favoring the morphology (forms and microforms), which leads to a multiplication of terms conferring a secondary role to the genesis and processes related to its formation. Therefore, we tried to develop a methodology to classify the karren and the related type of forms based on the formation processes that includes the type of sediment cover and the morphology. We consider three major groups of karren: i) those in which the dominant process (associated to dissolution) is related to running water; ii) those formed by the combined action of the runoff and of dissolution controlled by structural factors; iii) those with a mostly biochemical genesis, resulting from the action of dissolution (due to the persistence of water in flattened surfaces) and of the living organisms.

Keywords: Karren, genetic classification, formation processes, forms typology, Portuguese terminology.

Résumé - CLASSIFICATION ET TYPOLOGIE DES LAPIAZ. CONTRIBUTION POUR UNE TERMINOLOGIE DES FORMES KARSTIQUES. La bibliographie concernant les formes qui se développent dans les roches carbonatées a tendance à mettre en évidence les formes de karst dites majeures (dolines, ouvalas, poljés et formes fluvio-karstiques), prêtant moins d'attention aux formes de dissolution dites mineures composées par les formes lapiaires ou lapiaz (aussi appelés lapiés). Dans ce domaine, la bibliographie écrite en portugais ne fait pas exception. C'est de là que vient le choix de cet ensemble dans la vaste gamme de formes karstiques, au delà du fait que ce sont ces formes de dimension plus réduite qui mettent le mieux en évidence l'existence de processus de dissolution actif en surface et qui contribuent de façon décisive au fonctionnement hydrologique du karst sous-terrain. La majeure partie des classifications de lapiaz est essentiellement descriptive et privilégie la morphologie (formes et microformes), ce qui conduit à une multiplication des termes, attribuant un rôle secondaire à la genèse et aux processus liés à leur formation. C'est pour cela que l'on a tenté de bâtir une méthodologie de classification des lapiaz et une typologie des formes correspondantes, qui, partant des processus de formation, ajoute le type de couverture et la morphologie. On identifie trois grands ensembles de lapiaz: ceux pour lesquels le processus dominant (associé à la dissolution) est lié au ruissellement de l'eau; les formes lapiaires créées par l'action commune de l'écoulement et de la dissolution contrôlée par des facteurs structurels; les lapiaz d'origine essentiellement biochimique, résultants de l'action de la dissolution (par la présence permanente d'eau sur les surfaces déprimées) et des organismes vivants.

Mots-clés: Lapiaz, classification génétique, processus de formation, typologie des formes, terminologie en portugais.

\section{OS ESTUDOS PIONEIROS EM PORTUGAL}

Quando se fala em lapiás é incontornável referir o trabalho pioneiro de Ernest Fleury (Fleury, 1917) sobre o levantamento e caracterização dos lapiás calcários localisados a norte do Tejo. $\mathrm{O}$ autor considerou que as formações lapiares são bastante frequentes em Portugal e que, algumas, se encontram extremamente desenvolvidas sendo tão interessantes como as dos Alpes, do Jura ou do Karst.

O autor refere ainda (ob. cit., p. 133) que naquela época a lapiesação era geralmente explicada pela corrosão química secundada pela erosão mecânica das águas e, por vezes 
também, por certos organismos vegetais. Quanto à natureza e à estrutura das rochas, desempenham papéis variados que são quer favoráveis, quer restritivos.

No seu ensaio de terminologia lapiar, segundo o grau de evolução das formas, Fleury considera três tipos de formas: juvenis, de maturidade e senis (para além de referir também as formas enterradas, fósseis e rejuvenescidas). $\mathrm{O}$ autor considera que as formas juvenis são muito raras e esporádicas, resultando normalmente do rejuvenescimento de formas antigas recentemente desenterradas. Já as formas maduras são as mais frequentes encontrando-se sempre enraizadas, sendo esta distinção que exprime o estádio de evolução, mais do que a idade das formas.

Quanto aos factores lapiares, Fleury resume-os em três grandes conjuntos: 1 - os geográficos (onde inclui os climáticos e os topográficos); 2 - os petrográficos (que englobam os petrográficos propriamente ditos como a composição, dureza e solubilidade das rochas, os estruturais como as diaclases, fendas, fracturas, fissuras e juntas e os tectónicos como as falhas, dobras e outros acidentes); 3 - os biológicos (onde integra o papel desempenhado pelos musgos, liquenes, outros vegetais, animais entre os quais o Homem).

Outro trabalho fundamental dedicado ao carso em Portugal é a obra de Alfredo Fernandes Martins sobre o Maciço Calcário Estremenho (Martins, 1949). A propósito dos lapiás, o autor começa por considerar que estes são formas bem características e típicas do carso: "a rocha nua cinzelada, perfurada, e lavrada por sulcos mais ou menos profundos e estreitos, imprime um cunho particular às regiões calcárias" (ob. cit., p.143).

Embora Fernandes Martins discuta fundamentalmente questões relacionadas com as fases da lapiesação e a possível idade dos lapiás cobertos, em fase de exumação, existentes no Maciço, refere também alguns processos/factores ligados com a sua formação. A este propósito, distingue os lapiás dos abruptos e vertentes dos existentes nas superfícies aplanadas, embora todos revelem que a dissolução "segue na pista das águas de escorrência" (ob. cit., p.144), sendo tal mais evidente nas encostas onde as estrias se orientam com o declive. Faz ainda notar a sulcagem patente nas camadas pouco inclinadas, cortadas por sulcos mais ou menos paralelos, com perfil em V ou em U. Salienta igualmente as relações com a microtectónica, correspondendo as fendas abertas nas rochas a diaclases abertas pela corrosão. Outro aspecto interessante que o autor refere diz respeito ao facto de os lapiás enterrados continuarem a evoluir sob a terra rossa (embora não se tenham formado nessas condições), o que provoca o adoçamento das formas.

\section{CRITÉRIOS DE CLASSIFICAÇÃO DOS LAPIÁS}

Existem várias classificações dos lapiás, desde as obras pioneiras de Cvijic retomadas por Bogli (1960), até às tipologias definidas por outros autores estrangeiros (Sweeting, 1972; Nicod, 1972; Summerfield, 1991, baseado fundamentalmente em Jennings, 1985; Ford e Williams, 2007, entre outros) e portugueses (Crispim, 1987 ou Cunha, 1990).

Contudo, as classificações existentes são essencialmente descritivas, privilegiando as formas e microformas dos lapiás (o que pode levar a uma multiplicação quase infinita dos termos), mas secundarizando a génese e os processos ligados à sua formação. Concordamos inteiramente com Nicod (1972: 23) quando afirma que toda a classificação deve ter em conta os processos, motivo pelo qual distingue três conjuntos: os lapiás devidos ao escoamento (incluindo a humidificação por água de fusão da neve); os devidos à combinação de escoamento e de influências tectónicas; as vasques de dissolução e os lapiás cavernosos de origem bioquímica. 
Não é esta, no entanto, a opção da maioria dos autores que se dedicaram ao estudo da morfologia cársica. Por isso, Cunha (1990: 170) tentou integrar a classificação morfológica dos lapiás "nos grupos definidos por Bogli (1960) à semelhança do que tem sido feito por quase todos os que directa ou indirectamente se debruçaram sobre a problemática da geomorfologia cársica". Cunha (ob. cit., p.170-173) apresentou quatro conjuntos de lapiás (totalmente enterrados, enterrados em vias de exumação, resultantes de evolução sob cobertura e lapiasação actual e subactual), integrando em cada um alguns dos tipos morfológicos estabelecidos por Bogli (1960).

Parece-nos importante uma classificação dos lapiás quanto à cobertura pelas interessantes indicações que pode fornecer quanto à evolução sofrida pelas formas. No entanto, verifica-se frequentemente que os lapiás que evoluem actualmente sob cobertura são tipologicamente idênticos a formas superficiais, isto é, os processos que esculpiram o fundamental das formas podem ter sido os mesmos (embora actualmente a frescura dos contornos se apresente adoçada ou parcialmente obliterada). Quanto à cobertura é possível utilizar uma classificação mais simples, subdividindo os lapiás em: enterrados (ou cobertos), semi-enterrados (ou semi-cobertos) e nus.

A classificação dos lapiás quanto à morfologia é, contudo, a mais divulgada, baseando-se nos termos germânicos estabelecidos por Bogli (1960). Neste mesmo sentido foi elaborada a classificação dos tipos de lapiás simples apresentada por Sweeting (1972: 75), largamente baseada na de Bogli (ob. cit.), tendo a autora acrescentado, a cada tipo principal, dados referentes à dimensão média das formas, tipo de cobertura, disposição das rochas do substrato e forma das arestas.

Nesta classificação ${ }^{i}$ não se distinguem critérios que apontem directamente para a génese e processos envolvidos na elaboração dos lapiás. O caso talvez mais evidente é o respeitante aos Rundkarren cujo único critério de distinção consiste em apresentarem as formas suavizadas por evolução sob cobertura. Não se sabe, assim, se são formas de cripto-corrosão (como o fundo corroído das depressões que evoluíram sob cobertura), ou se são formas de um paleocarso (correspondendo, portanto, a formas de origem subaérea enterradas).

Outras classificações são mais completas (e complexas), como é o caso da discutida por J. Jennings (1985, in Summerfield, 1991: 149), e pretendem conjugar o tipo de cobertura e a morfologia dos lapiás.

São definidos quatro grandes conjuntos de formas que se desenvolvem: em calcários cobertos (que incluem dois tipos de lapiás); em calcários parcialmente cobertos (três tipos de lapiás); em calcários nus, subdivididos em dois subtipos referentes às que se formam devido à concentração do escoamento (três tipos de lapiás), e às que se desenvolvem através de uma humidificação não concentrada (cinco tipos de lapiás).

Num artigo dedicado aos lapiás do carso do Algarve, Crispim (1987) propõe uma classificação onde tenta conciliar o tipo de cobertura e as condicionantes estruturais. São apresentados oito tipos de lapiás: residuais, enterrados, semi-enterrados, de arestas vivas, de diaclases, de juntas de estratificação, em brechas e megalapiás. A maior parte dos tipos definidos por Bogli (1960) surgem apenas no ponto referente às formas menores de corrosão dos lapiás, subdividido em formas de carso nu, formas de carso enterrado e aspectos epidérmicos (Crispim, 1987: 3-6).

Como nenhuma das classificações expostas apresenta como critério fundamental os processos que estão na génese das formas lapiares, parece-nos que a metodologia a seguir poderia ser a de, partindo dos processos, acrescentar o tipo de cobertura e as formas, conforme o esquema que se apresenta na fig. 1 . 


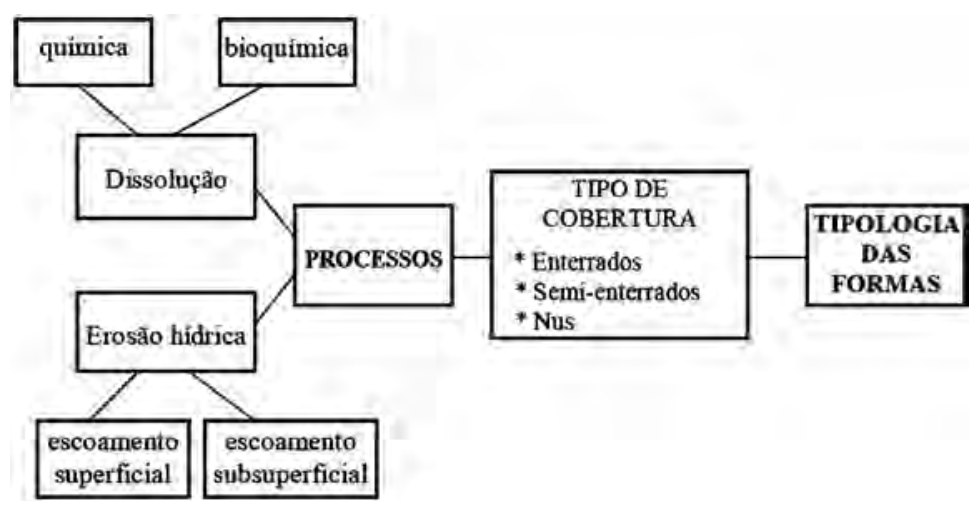

Fig. 1 - Metodologia de classificação das formas lapiares.

Fig. 1 - Methodology of karren classification.

Neste esquema subdividiu-se a erosão hídrica apenas nos dois grandes componentes do escoamento (superficial e subsuperficial), embora existam, como se sabe, vários tipos de escorrência difusa e concentrada que dão lugar a variações na forma dos lapiás.

A ideia de classificar os lapiás com base fundamentalmente nos processos que controlam a sua formação não é inédita. Segundo Ford e Williams (2007) o próprio Bogli (1980) terá escrito que "The multiplicity of possible karren forms makes a morphological system endless, while a genetic one allows a meaningful collection". Aqueles autores também concordam com o princípio que uma classificação genética é preferível a uma morfológica, mas acabam por adoptar uma classificação morfológica por considerarem que a génese de muitos lapiás ainda não é bem compreendida e porque muitos resultam de uma combinação de processos.

\section{TERMINOLOGIA E TIPOLOGIA DOS LAPIÁS}

Após esta breve reflexão sobre a classificação dos lapiás, permanecem os problemas relacionados com a terminologia em português, que se reporta sempre à terminologia internacionalmente mais divulgada em alemão. Apresenta-se aqui uma proposta de termos, utilizados por Rodrigues (1998) em trabalho dedicado ao Maciço Calcário Estremenho, acrescentando-se uma pequena descrição dos processos envolvidos, tipo de evolução e características morfológicas ${ }^{\text {ii }}$.

Os principais tipos de lapiás em que o processo dominante (associado à dissolução) se relaciona com o escoamento superficial da água, são os lapiás em sulcos ou regueiras (Rinnenkarren), os lapiás meandriformes (Meanderkarren), os lapiás em caneluras (Rillenkarren), os lapiás em sulcos suavizados (Hohlkarren) e os lapiás em sulcos arredondados (Rundkarren).

Os lapiás em sulcos ou regueiras (Rinnenkarren) são devidos a processos de sulcagem. As formas são semelhantes aos sulcos que se desenvolvem noutros tipos rochosos devidos ao escoamento concentrado superficial, pelo que a sua largura aumenta normalmente para jusante. Desenvolvem-se em superfícies rochosas inclinadas e apresentam dimensões variadas, em média com 30 a $50 \mathrm{~cm}$ de profundidade e 20 a $50 \mathrm{~cm}$ de largura. Podem apresentar padrões diversos associados à drenagem, embora sejam mais frequentes os padrões paralelos (seguindo o declive) e dendríticos. As arestas são normalmente agudas mas o fundo pode ser leve- 
mente arredondado (fig. 2). Nos sulcos de maior dimensão, já equivalentes a ravinas, quando as vertentes do canal são muito íngremes podem apresentar lapiás em caneluras (Rillenkarren). Os lapiás em sulcos foram associados ao termo Rillenkarren por Nicod (1972: 23) e Cunha (1990: 171), mas a generalidade dos autores segue a tipologia de Bogli (1960).

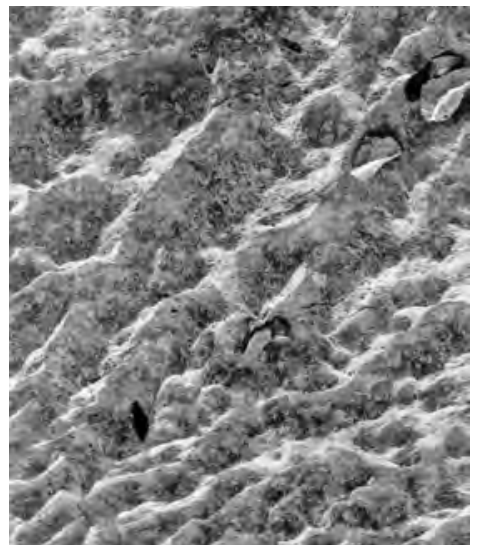

Fig. 2 - Lapiás em sulcos ou regueiras. Vertente oriental da Serra de Candeeiros, Bezerra, Maciço Calcário Estremenho.

Fig 2 - Rinnenkarren. Eastern slope of Serra de Candeeiros, Bezerra, Maciço Calcário Estremenho.

Os lapiás meandriformes (Meanderkarren) são uma variedade de lapiás em sulcos que se desenvolvem em superfícies rochosas apenas levemente inclinadas (fig. 3). Devido a uma diminuição da velocidade da escorrência é frequente encontrar a sua combinação com formas em pias e alvéolos de dissolução localizadas em pontos onde existe uma permanência mais demorada da água e um predomínio da corrosão química.

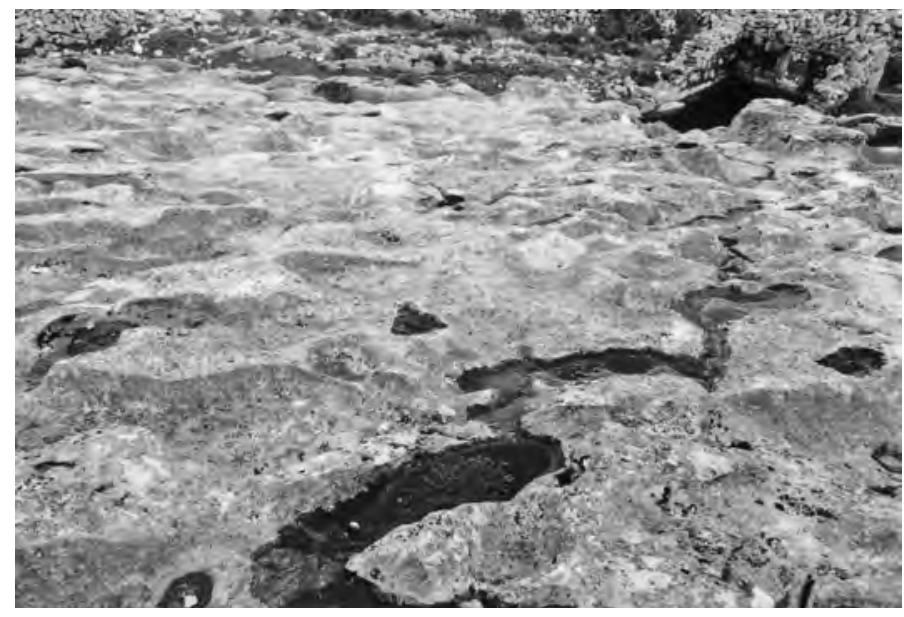

Fig. 3 - Lapiás meandriforme. Vertente oriental da Serra de Candeeiros, Bezerra, Maciço Calcário Estremenho.

Fig. 3 - Meanderkarren. Eastern slope of Serra de Candeeiros, Bezerra, Maciço Calcário Estremenho. 
Os lapiás em caneluras (Rillenkarren) desenvolvem-se em superfícies rochosas fortemente inclinadas e em paredes verticais, devido a fluxos canalizados. Existem dúvidas quanto aos factores que influenciam a sua localização, apontando-se, entre outros a influência de processos biocársicos (Fiol et al., 1996) ou a percentagem de calcite existente na rocha e no cimento micrítico (Vincent, 1996). Possuem um padrão paralelo, rectilíneo e regularmente espaçado. Transversalmente o seu perfil pode ser em $\mathrm{U}$ ou em $\mathrm{V}$, possuindo arestas vivas ou levemente arredondadas. A dimensão média das formas é de $1 \mathrm{a} 2 \mathrm{~cm}$ de profundidade e 20 a $50 \mathrm{~cm}$ de largura.

Os lapiás em sulcos suavizados (Hohlkarren) são idênticos aos lapiás em sulcos, mas apresentam diferenças devidas a uma evolução semi-enterrada. Assim, os sulcos têm tendência para alargar em direcção à base, provavelmente devido à presença de solos e matéria orgânica que mantêm a rocha em contacto prolongado com águas ácidas. Predominam em superfícies rochosas inclinadas e suavemente inclinadas, possuindo, normalmente, dimensões médias superiores aos sulcos em rocha nua.

Os lapiás em sulcos arredondados (Rundkarren) são o resultado de formas de sulcagem que evoluem por dissolução sob cobertura. Ocorrem em superfícies rochosas inclinadas, possuem formas esbatidas e, eventualmente, degradadas por acção das raízes das plantas e são devidos aos vários tipos de escoamento subsuperficial. Apresentam dimensões médias semelhantes ou ligeiramente inferiores aos lapiás em sulcos que evoluem à superfície.

Embora constituam formas de pormenor, as ondulações de dissolução de pequeno comprimento de onda (solution ripples) desenvolvem-se transversalmente à direcção do escoamento em superfícies inclinadas. Podem ter uma altura de 2 a $3 \mathrm{~cm}$ e uma extensão horizontal superior a $10 \mathrm{~cm}$, apresentando o lado mais declivoso exposto ao fluxo.

Um segundo conjunto de formas lapiares é formado pela acção conjunta do escoamento e da dissolução, controlada por factores estruturais. Dele fazem parte os lapiás em fendas ou ranhuras (Kluftkarren) $)^{\mathrm{iii}}$, os lapiás em mesa (Karrentisch ou Flachkarren), os corredores de dissolução (bogaz) e os lapiás em agulhas (Spitzkarren).

Os lapiás em fendas ou ranhuras (Kluftkarren) são formas orientadas pela presença de fracturas existentes nas rochas calcárias. Estas descontinuidades estruturais podem corresponder a falhas, diaclases, juntas de estratificação ${ }^{\text {iv }}$, etc. (fig. 4). Desenvolvem-se predomi-

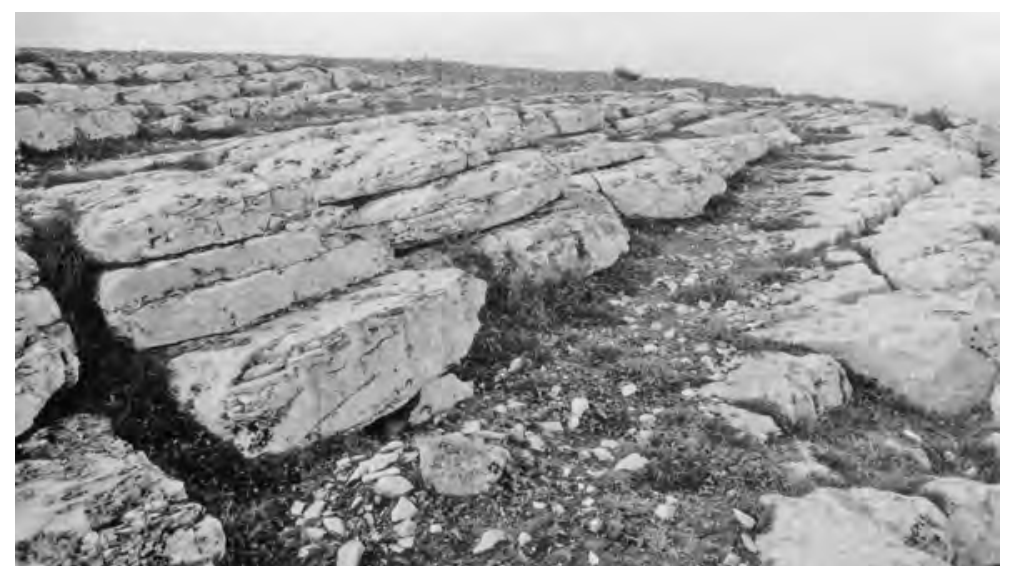

Fig. 4 - Lapiás em fendas ou ranhuras. Topo da Costa de Alvados, Maciço Calcário Estremenho.

Fig. 4 - Kluftkarren. Top of Costa de Alvados slope, Estremadura Limestone Massif. 
nantemente em superfícies rochosas horizontais ou sub-horizontais com exposição subaérea, embora possam evoluir sob cobertura parcial ou total. Possuem dimensões variadas em função da progressão dos processos de dissolução, desde poucos centímetros a vários metros de profundidade e largura até 2 metros (fig. 5). Inicialmente as fendas apresentam formas em V (Dzulynski et al., 1988), podendo, com o alargamento progressivo, mostrar formas em U ou de fundo plano (nuas ou parcialmente entulhadas por materiais finos e clastos calcários).

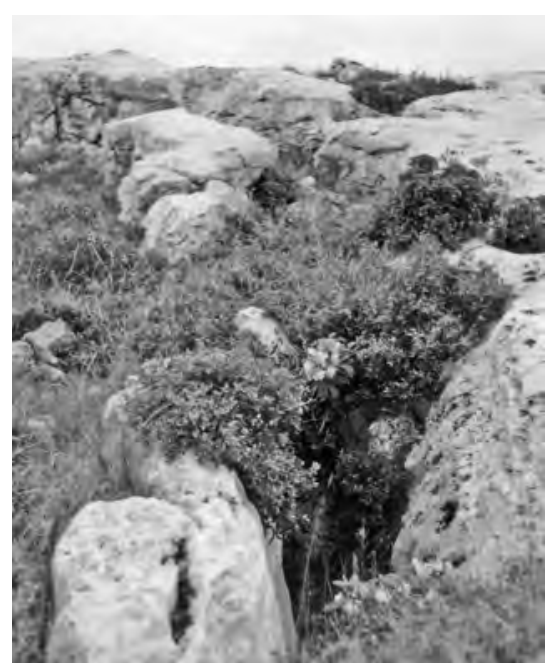

Fig. 5 - Lapiás em fendas ou ranhuras. Topo norte da Serra de Candeeiros (Serra da Pevide), Maciço Calcário Estremenho.

Fig. 5 - Kluftkarren. Northern top of Serra de Candeeiros (Serra da Pevide), Estremadura Limestone Massif.

Os lapiás em mesa (Karrentisch ou Flachkarren) são lapiás em fendas que se desenvolvem segundo um padrão de fracturação ortogonal, definindo blocos calcários com formas superficiais quadrangulares ou rectangulares (fig. 6). Conservam-se com mais facilidade em calcários maciços, sendo a dimensão das mesas função da densidade da fracturação.

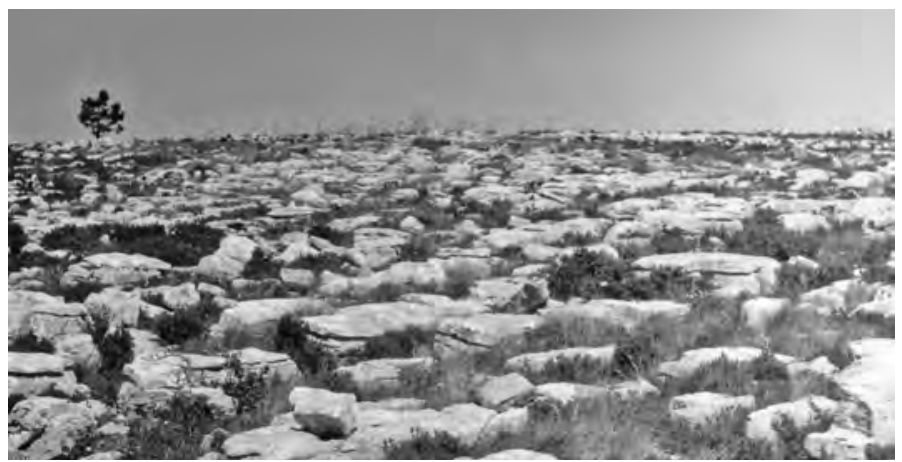

Fig. 6 - Lapiás em mesa. Planalto de $\mathrm{St}^{\circ}$ António, Maciço Calcário Estremenho.

Fig. 6 - Karrentisch or Flachkarren. Planalto de St António, Estremadura Limestone Massif. 
Os corredores de dissolução (bogaz) são, frequentemente, o resultado da progressiva abertura das fendas lapiares por dissolução. Em certos casos podem corresponder também ao abatimento do tecto de condutas cársicas (normalmente fósseis), situadas próximo da superfície topográfica. Possuem grandes dimensões (largura e profundidade superior a $2 \mathrm{~m}$ ) e apresentam o fundo plano normalmente coberto por materiais diversos propícios ao desenvolvimento da vegetação. Casos particulares de carsos com lapiás gigantes e corredores de dissolução (Karstgassen), são referidos, por exemplo, por Julian et al. (1978).

Os lapiás em agulhas (Spitzkarren) são característicos pelas suas formas aguçadas e rendilhadas que podem atingir vários metros (fig. 7). No pormenor podem apresentar arestas em lâmina (Karrengrat) ou em bico (Karrendorn). A sua génese é controlada pela tectónica e pela litologia, pois desenvolvem-se em calcários intensamente fracturados, ao longo das juntas de estratificação de camadas com pendor muito forte e em rochas com elevada percentagem de carbonatos.

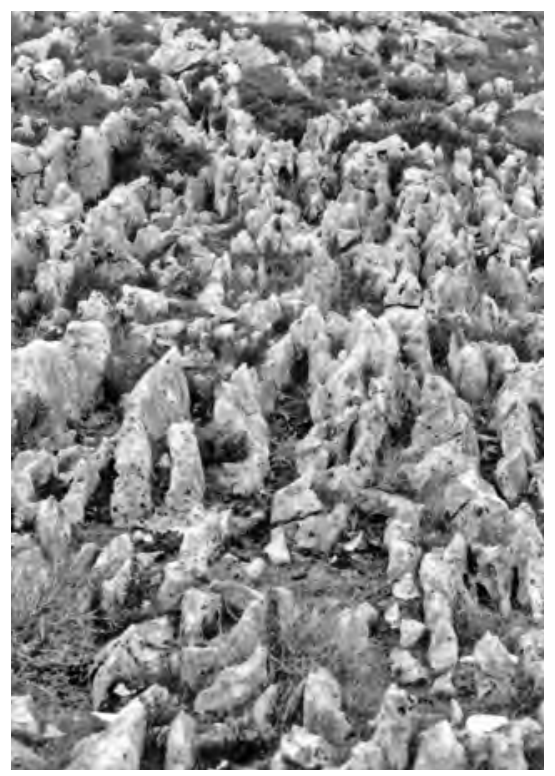

Fig. 7 - Lapiás em agulhas. Vertente oriental da Serra de Candeeiros, Maciço Calcário Estremenho. Fig. 7 - Spitzkarren. Eastern slope of Serra de Candeeiros, Maciço Calcário Estremenho.

Por último, um terceiro conjunto de lapiás tem uma origem fundamentalmente bioquímica, resultante da acção conjunta da dissolução (por permanência da água em superfícies deprimidas) e dos organismos vivos. Salientam-se as bacias ou pias de dissolução (Kamenitzas ou solution pans or basins) ${ }^{\mathrm{v}}$, os alvéolos de dissolução ou lapiás alveolares (Grubchenkarren), os alvéolos de dissolução suavizados (Deckenkarren) e os lapiás em ninhos ou favos de abelha (honeycomb e rainpit microforms).

As bacias ou pias de dissolução (Kamenitzas) desenvolvem-se em estruturas horizontais (onde possuem formas simétricas), ou subhorizontais (normalmente com formas dissimétricas). Incluem depressões geralmente circulares com fundo em calcário nu ou coberto por materiais predominantemente finos e pouco espessos. Constituem locais de permanência mais ou menos prolongada da água da chuva cuja agressividade pode ser reforçada por acção 
orgânica (quando isso acontece as pias de dissolução alargam junto à base). Em superfícies inclinadas as bacias dissimétricas podem dar lugar a formas abertas e mesmo a pequenos sulcos alimentados pela água concentrada na bacia (fig. 8). Possuem dimensões variadas, mas são normalmente mais largas (poucos centímetros a $3 / 4 \mathrm{~m}$ ) do que profundas (poucos centímetros a pouco mais de $50 \mathrm{~cm})$.

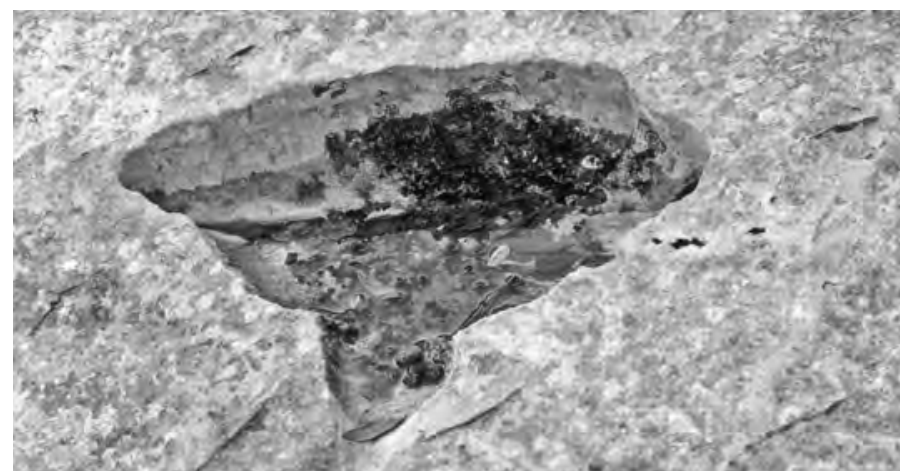

Fig. 8 - Bacia ou pia de dissolução dissimétrica. Maciço Calcário Estremenho.

Fig. 8 -Asymmetrical solution pan or basin (also Kamenitza). Estremadura Limestone Massif.

Os alvéolos de dissolução ou lapiás alveolares (Grubchenkarren) têm uma génese idêntica à das pias, embora por vezes sejam, de forma mais evidente, também condicionados por pequenas diferenças litológicas ou pela microfracturação. No entanto, a acção orgânica (líquenes, algas, musgos, raízes, etc.) parece desempenhar um papel dominante na sua localização (fig. 9). São formas centimétricas que se podem desenvolver qualquer que seja o declive das superfícies.

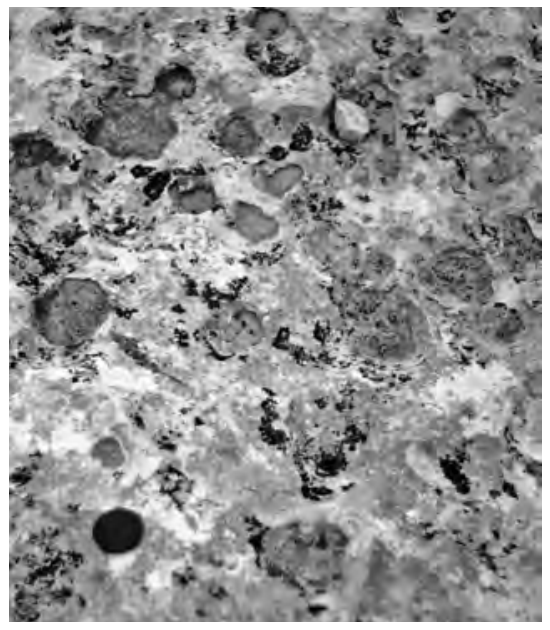

Fig. 9 - Alvéolos de dissolução ou lapiás alveolar. Topo norte da Serra de Candeeiros (Serra da Pevide), Maciço Calcário Estremenho.

Fig. 9 - Grubchenkarren. Northern top of Serra de Candeeiros (Serra da Pevide), Estremadura Limestone Massif. 
Os alvéolos de dissolução suavizados (Deckenkarren) são formas alveolares que evoluem sob cobertura. Possuem, por isso, arestas boleadas, sendo a sua origem normalmente atribuída à acção directa das raízes de plantas arbustivas e arbóreas.

Os lapiás em ninhos ou favos de abelha são microformas com poucos milímetros a alguns centímetros que podem evoluir para formas alveolares. Em vertentes suaves talhadas em calcário nu podem ser iniciados pela acção mecânica e química das gotas de chuva (rainpit). A coalescência destas formas elementares de variada dimensão pode dar lugar a um micromodelado irregular e cariado (fig. 10), ou mesmo à ocorrência de rochas perfuradas (Kavernosenkarren).

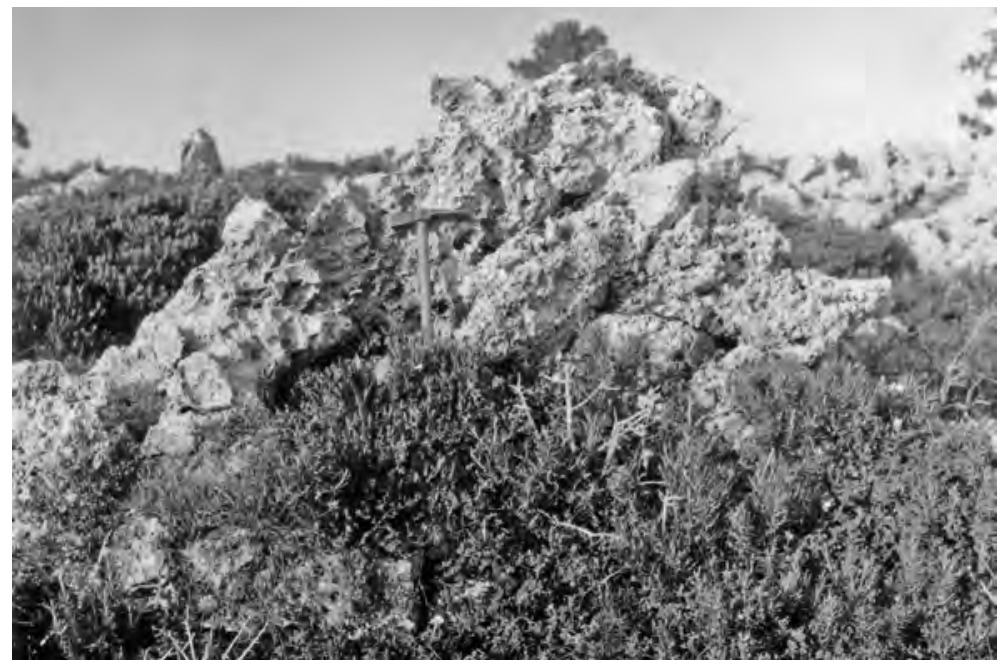

Fig. 10 - Lapiás em ninhos ou favos de abelha. Cadouços, depressão de Alvados, Maciço Calcário Estremenho.

Fig. 10 - Kavernosenkarren. Cadouços, Alvados depression, Estremadura Limestone Massif.

Esta tipologia, baseada na classificação genética apresentada, foi aplicada no estudo dos lapiás do Maciço Calcário Estremenho (Rodrigues, 1998), tendo sido relativamente fácil distinguir as formas produzidas essencialmente por escoamento superficial das devidas à infiltração da água ao longo de superfícies de descontinuidade (como as fracturas, diaclases e juntas de estratificação), ou das resultantes fundamentalmente de processos bioquímicos.

\section{BIBLIOGRAFIA}

Bogli A (1960) Kalklosung und Karrenbildung. Zeitschrift für Geomorphologie, suppl. 2 (Int. Beitrage zur Karstmorphologie), Berlin-Nikolassee: 4-21.

Crispim J (1987) Os lapiás do carso do Algarve. Sociedade Portuguesa Espeleologia, 8: 3-8.
Cunha L (1990) As Serras Calcárias de CondeixaSicó-Alvaiázere. Estudo de Geomorfologia. INIC, Geog. Física, 1, Coimbra.

Dzulynski S, Gil E, Rudnicki J (1988) Experiments on Kluftkarren and related lapies forms. Zeitschrift für Geomorphologie N.F., 32(1): 1-16. 
Fiol L, Fornos J, Ginés A (1996) Effects of biokarstic processes on the development of solution rillenkarren in limestone rocks. Earth Surface Processes and Landforms, 21: 447-452.

Fleury E (1917) Notes sur l'érosion en Portugal. II - Les lapiés des calcaires au Nord du Tage. Extracto das Comunicações do Serviço Geológico de Portugal, Lisboa, XII: 127-274.

Ford D, Williams P (2007) Karst Hydrologeology and Geomorphology. John Wiley \& Sons, Ltd, Chichester.

Julian M, Martin J, Nicod J (1978) Les karsts méditerranéens. Méditerranée, t. 32, 1-2 (Pays calcaires méditerranéens): 115-131.

Martins A F (1949) Maciço Calcário Estremenho. Contribuição para um estudo de geografia fisica. Coimbra.

Nicod J (1972) Pays et paysages du calcaire. Press Universitaire de France, sup. 7, Paris.

Rodrigues M L (2003a) Algumas características geomorfológicas do Maciço Calcário Estremenho e suas implicações no desenvolvimento das formas cársicas. Sustentabilidade e Património Cársico, Livro de Actas do IV
Congresso Nacional de Espeleologia in Galvão, J.R. e Emanuel, F. ed., Leiria: 67-73.

Rodrigues M L (2003b) Projecto CARSO - Terminologia e Glossário das formas, formações e processos cársicos. Sustentabilidade e Património Cársico, Livro de Actas do IV Congresso Nacional de Espeleologia in Galvão, J.R. e Emanuel, F. ed., Leiria: 91-98.

Rodrigues M L (1998) Evolução geomorfológica quaternária e dinâmica actual. Aplicações ao ordenamento do território. Exemplos no Maciço Calcário Estremenho. Dissertação de Doutoramento em Geografia Física, Universidade de Lisboa, Lisboa.

Rodrigues M L (1988) As depressões de Minde e de Alvados. Depósitos e evolução quaternária das vertentes. Dissertação de Mestrado em Geografia Física e Regional, F.L.L., Lisboa.

Summerfield M (1991) Global geomorphology. Longman Scientific \& Technical, Harlow.

Sweeting M (1972) Karst landforms. Macmillan, Londres.

Vincent P (1996) Rillenkarren in the British Isles. Zeitschrift für Geomorphologie N.F., Berlin-Stuttgart, 40(4): 487-497.

i Adoptada, numa versão em língua castelhana, pelo Departamento de Geomorfología y Geotectónica, Facultad de Ciencias da Universidad de Zaragoza.

ii Deixa-se para altura mais oportuna o estabelecimento de um quadro sinóptico completo dos tipos de lapiás, que nos parece dever ser o resultado de discussões alargadas no seio da comunidade científica.

iii Designados por lapiás de diaclases (Crispim, 1987) e fendas de corrosão (Cunha, 1990).

iv Crispim (1987) considera os lapiás de juntas de estratificação como um tipo separado, distinguindo as formas que se desenvolvem em estrutura horizontal, das existentes em estruturas inclinadas.

v Também designadas por escudelas de corrosão (Crispim, 1987) e vascas de corrosão química (Cunha, 1990). 